\title{
A INDÚSTRIA CERÂMICA PORTUGUESA E A INTEGRAÇÃO EUROPEIA: BREVE CONTRIBUIÇÃO PARA UM BALANÇO ${ }^{1}$
}

\author{
PAUlo AREOSA FeiO ${ }^{2}$
}

Resumo - A cerâmica, tal como outros ramos «tradicionais» da indústria transformadora, debate-se ainda hoje com o impacto provocado pela crescente abertura internacional da economia portuguesa e pela globalização dos mercados, que a integração europeia acelerou. A partir de uma análise sumária da sua evolução ao longo dos últimos anos, pretende-se evidenciar as características gerais da reacção deste ramo às novas condições de concorrência entretanto criadas. Quer em fases de crise, quer de expansão da procura, desenvolveram-se diferentes estratégias empresariais, que ora prolongam a dinâmica tradicional de exploração dos baixos custos de produção, o que reforça a incapacidade das empresas portuguesas de fazerem face às flutuações da procura internacional, ora procuram a incorporação crescente de novos factores de competitividade e o reforço do seu posicionamento nos mercados internacionais. Este processo conduziu à reconfiguração geográfica da produção, acentuando a sua polarização em áreas de grande especialização produtiva. Esse facto tem contribuído para o desenvolvimento de condições territoriais favoráveis à emergência de novas condições de competitividade, que as políticas públicas não podem deixar de continuar a estimular.

Palavras-chave: indústria, cerâmica, globalização, território, vantagens comparativas, competitividade.

Résumé - L'industrie Ceramique Portuguaise et L'integration Europeenne. La production céramique, tout comme que d'autres branches traditionnelles de l'industrie de transformation, se trouve de nos jours confrontée aux impacts provoqués par l'ouverture internationale croissante de l'économie portugaise et par la mondialisation des marchés que l'intégration européenne a accélérée.

A partir d'une analyse sommaire, nous voulons mettre en évidence les caractéristiques de l'évolution de cette branche au cours des dernières années et face aux nouvelles conditions de concurrence créées entre-temps.

Aussi bien en période de crise qu'en période d'expansion, de différentes stratégies compétitives se sont développées. Les unes prolongent la dynamique traditionnelle d'exploitation des bas coûts de production, ce qui se traduit par le maintien de l'incapacité de ces entreprises à faire face aux fluctuations de la demande internationale, tandis que les autres recherchent l'incorporation croissante de nouveaux facteurs de compétitivité, ce qui a permis de mieux se placer sur les marchés internationaux.

Ces processus ont conduit à une reconfiguration géographique de la production, accentuant la polarisation en régions de grande spécialisation productive, où des conditions favorables à l'émergence de nouveaux facteurs de compétitivité sont apparues. Une politique adéquate menée par les pouvoirs publics doit être maintenue.

Mots-clés: industrie, produits céramiques, globalisation, territoire, avantages comparatifs, compétitivité.

\footnotetext{
1 Este artigo foi efectuado no âmbito do projecto «Desenvolvimento industrial e território», JNICT, $\mathrm{PCSH} / \mathrm{C} / \mathrm{GEO} / 715 / 93$.

2 Assistente no Departamento de Geografia da Faculdade de Letras da Universidade de Lisboa e investigador do Centro de Estudos Geográficos. Alameda da Universidade 1699 Lisboa codex; tel: (01) 79402 18; fax: (01) 79386 90, e-mail: ulflpaf@cc.fc.ul.pt
} 
Quase dez anos após a adesão de Portugal à Comunidade Económica Europeia, o debate sobre o impacto desse acontecimento crucial da evolução recente do país sobre o tecido produtivo nacional continua em aberto. Desde logo porque se trata de um período complexo, em que aos efeitos directamente resultantes da integração europeia se associam os que derivam de uma mutação rápida do quadro económico internacional, fortemente marcado pelas tendências de globalização.

Numa perspectiva muito geral, não parece difícil antever que o cenário de uma eventual não-adesão seria bem pouco optimista: as notórias debilidades de uma economia relativamente fragilizada e simultaneamente fortemente aberta ao exterior far-se-iam certamente sentir neste período. Mas a questão que parece mais relevante é a de saber se as políticas desenvolvidas ao longo destes dez anos, sustentadas em importantes fluxos financeiros comunitários, contribuíram para que o país debelasse algumas das suas tradicionais fragilidades e construísse novas vantagens competitivas de modo a encarar o novo quadro económico internacional de uma forma mais animadora.

Nesta nota debruçar-nos-emos sobre a evolução recente da indústria cerâmica. O carácter limitado desta análise, incidindo sobre um ramo que representa pouco mais de $2 \%$ do emprego industrial do país, não exclui, contudo, que algumas das suas conclusões se possam revelar úteis tanto para outras abordagens sectoriais como para uma visão de conjunto das relações entre as dinâmicas industriais e os processos de desenvolvimento regional, em virtude da importância dos impactos em tecidos sócio-económicos locais que decorrem da grande concentração espacial deste ramo.

Está implícita, nesta abordagem, a ideia que o desenvolvimento dos ramos tradicionais é um aspecto crucial na afirmação da indústria nacional. Como bem demonstraram os debates desenvolvidos a propósito do relatório Porter, a definição de uma estratégia para o reforço da competitividade da indústria nacional não se pode confinar ao aprofundamento da especialização nesses ramos tradicionais, tanto mais que eles se confrontam, em geral, com um fraco crescimento da procura global. Mas terá necessariamente que tomar em conta as potencialidades daqueles que são, ainda hoje, pilares fundamentais da capacidade produtiva do país. Ao carácter tradicional desses sectores não se associam apenas as vantagens comparativas em fase de rápida erosão, como o trabalho barato e pouco qualificado. Dele advêm igualmente algumas das suas vantagens potenciais, reflectidas por exemplo numa cultura técnica fortemente enraizada, num conhecimento dos mercados ou em mecanismos estabelecidos de difusão de inovação, que urge potenciar através de políticas de incentivo ao upgrading tecnológico ou da gestão empresarial. A avaliação do efeito das políticas industriais destes últimos anos, ainda que na óptica parcelar do reforço da competitividade, não pode, por isso, prescindir da análise da evolução específica destes ramos, a par naturalmente dos progressos efectuados no plano da diversificação ou da criação de novos «pólos» de especialização.

A análise que se segue desenvolve-se em dois níveis complementares. Por um lado, estudar-se-á a evolução do ramo no seu conjunto, ao longo dos últimos anos, procurando evidenciar como essa evolução reflecte quer os efeitos de diferentes conjunturas económicas do País - alternância de fases de clara expansão com outras de retracção ou mesmo de crise acentuada -, quer os efeitos das flutuações do quadro internacional, nomeadamente no domínio da procura, tão importantes 
num sector que tem na exportação uma parte considerável do seu mercado. Por outro lado, procurar-se-á, a partir de uma análise sumária das características essenciais do sector, pôr em evidência como aquela evolução geral esconde, de facto, realidades distintas tanto no plano das empresas como no dos diferentes tecidos regionais.

\section{UMA PANORÂMICA GERAL SOBRE A EVOLUÇÃO DO SECTOR DA CERÂMICA FINA}

O sector da cerâmica fina tem sido apontado em diversos estudos sobre a competitividade da indústria transformadora nacional (CCE, 1990; MONITORY Co, 1994) como um dos que apresenta fortes potencialidades no quadro de uma economia progressivamente mais integrada internacionalmente. No entanto, essas apreciações não têm tradução imediata numa avaliação da evolução recente dos principais indicadores do ramo ${ }^{3}$. Os anos 80 são marcados por uma trajectória irregular, mas grosso modo acompanham as tendências gerais da economia nacional: na primeira metade são bem visíveis ainda os sintomas de crise, enquanto a segunda reflecte já a expansão geral verificada (quadro I).

Algumas particularidades importa, contudo, registar. No período que precede a adesão, a tendência recessiva é essencialmente evidente no plano do $\mathrm{VAB}$, não se traduzindo de modo notório no volume de emprego do ramo. O indicador de síntese utilizado pelo INE revela mesmo um acréscimo, ainda que ténue, do volume da produção. Apenas no ano de 1985 todos os indicadores são reveladores de uma situação de crise no sector. Parece, pois, possível concluir que neste período a conjuntura geral desfavorável se terá reflectido sobretudo no plano da produtividade.

Quadro I - Evolução do sector da cerâmica fina na década de 80

Tableau I - Evolution de la branche des produits céramiques dans les années quatre-vingt

\begin{tabular}{|l|c|c|c|c|c|}
\hline & anos & emprego & $\begin{array}{c}\text { VAB (preços } \\
\text { constantes de } \\
1980)\end{array}$ & $\begin{array}{c}\text { índice de produção } \\
\text { industrial INE } \\
1981=100\end{array}$ & \multicolumn{1}{|l}{} \\
\hline & 1981 & 12875 & 4638 & 100 & \\
\hline & 1982 & 13570 & 4634 & 116 & \\
\hline & 1983 & 13792 & 4365 & 126 & \\
\hline & 1984 & 13959 & 4528 & 127 & \\
\hline & 1985 & 13895 & 4210 & 127 & \\
\hline & 1986 & 14428 & 4575 & 141 & \\
\hline & 1987 & 14993 & 5602 & 157 & \\
\hline & 1988 & 15325 & 5667 & 174 & \\
\hline & 1989 & 14642 & 5383 & 179 & \\
\hline
\end{tabular}

fonte: Estatísticas Industriais, INE

A leitura conjunta dos elementos relativos à produção e ao comércio externo (quadro 2) prefigura, todavia, uma reacção global do sector que não é exclusivamente dominada por estratégias defensivas de adaptação à escassez da procura. Se,

\footnotetext{
${ }^{3}$ Para a análise desenvolvida neste ponto, considera-se o ramo 361 da CAE (versão 1973), que engloba a fabricação de porcelana, faiança, grés e olaria de barro, como representativo da cerâmica fina.
} 
por um lado, são evidentes os indícios de flexibilização na gestão do emprego, que terá acentuado a precarização das relações contratuais e a diminuição do nível geral das remunerações, por outro são também nítidos os esforços desenvolvidos na diversificação de mercados, bem patentes na evolução das exportações.

Quadro II - O comércio externo no sector da cerâmica

Tableau II - Le commerce extérieur dans la branche des produits céramiques

\begin{tabular}{|c|c|c|c|c|}
\hline períodos & $\begin{array}{c}\text { variação das } \\
\text { exportações } \\
\text { taxa média } \\
\text { anual }(\%)\end{array}$ & $\begin{array}{c}\text { variação das } \\
\text { importações } \\
\text { taxa média } \\
\text { anual }(\%)\end{array}$ & $\begin{array}{c}\text { Quota dos produtos } \\
\text { cerâmicos nas ex- } \\
\text { portações portugue- } \\
\text { sas }(\%)\end{array}$ & $\begin{array}{c}\text { taxa de cobertura } \\
\text { das importações } \\
\text { pelas exportações } \\
\text { de prod. cerâmicos }\end{array}$ \\
\hline $1983-85$ & 56.7 & 9.1 & 1.31 & 5.04 \\
\hline $1986-88$ & 28.0 & 90.8 & 1.75 & 2.61 \\
\hline $1989-91$ & 24.2 & 11.9 & 2.08 & 2.69 \\
\hline $1992-94$ & 5.2 & -0.4 & 2.34 & 2.87 \\
\hline
\end{tabular}

fonte: INE - Estatísticas do Comércio Externo; ICEP

Este ciclo recessivo parece já claramente debelado no ano de 1986, que marca o início de uma fase de grande crescimento. Os primeiros anos de integração europeia coincidem, pois, com uma fase de franca expansão do sector, caracterizada não só pelo aumento da produção, mas reflectindo-se igualmente no crescimento do volume de emprego global e num dinamismo empresarial assinalável.

Noutro trabalho (FEIO, 1995) tivemos já ocasião de referir o número elevado de empresas constituídas depois de 1985, período no qual se conjugam processos muito diferenciados: por um lado, os de carácter endógeno nas áreas de forte especialização produtiva, que em muitos casos assumem as formas típicas do spin-off (novas empresas criadas por trabalhadores qualificados do ramo, geralmente provenientes das maiores empresas); por outro, processos exógenos a essas regiões, em que tanto o capital estrangeiro como os grupos económicos nacionais assumem um papel motor. Nesses anos de alguma euforia, grande parte das empresas beneficiou de condições envolventes bastante favoráveis, tanto na óptica dos mercados, com a procura nacional em franca recuperação e a procura externa a permitir um crescimento acentuado das exportações, como do lado das condições de produção, onde os efeitos de uma política fortemente assistencial se faziam sentir. Tais condições devem ter-se sobreposto, pelo menos numa primeira fase, às dificuldades criadas pela concorrência acrescida, movida nomeadamente pelas empresas provenientes de outros países da Europa meridional, cuja entrada no mercado nacional é bem patente na evolução das importações.

A transição para a década de noventa revela, entretanto, um novo período de dificuldades marcado, entre outros aspectos, por algumas falências, pela diminuição do volume de emprego e por um nítido abrandamento do ritmo de crescimento das exportações.

Como quase sempre acontece, é em conjunturas menos favoráveis que vêm ao de cima as debilidades de um tecido produtivo que se expande muito, mas nem sempre com a necessária sustentabilidade. 
Em termos de sub-sectores são visíveis alterações muito sensíveis para um tão curto lapso de tempo (quadro III). O sub-sector das porcelanas e faianças decorativas é o que apresenta uma evolução mais positiva, afirmando-se como a principal componente das exportações do ramo. Pelo contrário, o sub-sector da azulejaria conhece uma evolução inversa, perdendo a sua posição cimeira na produção e nas exportações. Neste caso é bem evidente a influência da concorrência estrangeira no próprio mercado nacional, associada à «invasão» dos grandes produtores europeus (Espanha e Itália, nomeadamente) após a adesão, e a perda de alguma competitividade nos mercados externos, tornando os valores das exportações e das importações praticamente equivalentes. Nos restantes sub-sectores, as alterações são menos pronunciadas, mantendo, nomeadamente após a integração europeia, uma posição estável tanto no mercado nacional como no exterior.

Quadro III - Importância de diversos tipos de produtos na produção do ramo e no comércio externo

Tableau III - Importance de plusieurs produits céramiques dans la production et le commerce extérieur

\begin{tabular}{|c|c|c|c|c|c|c|c|c|}
\hline & \multicolumn{2}{|c|}{$\begin{array}{c}\text { pavimentos e reves- } \\
\text { períodos }\end{array}$} & \multicolumn{2}{|c|}{ louças sanitárias } & \multicolumn{2}{c|}{$\begin{array}{c}\text { porcelanas e faianças } \\
\text { domésticas }\end{array}$} & \multicolumn{2}{c|}{$\begin{array}{c}\text { porcelanas e faianças } \\
\text { decorativas }\end{array}$} \\
\hline & $\begin{array}{c}\% \text { da } \\
\text { Produção }\end{array}$ & $\begin{array}{c}\text { Rácio } \\
\text { Exp/Imp }\end{array}$ & $\begin{array}{c}\% \text { da } \\
\text { Produção }\end{array}$ & $\begin{array}{c}\text { Rácio } \\
\text { Exp/Imp }\end{array}$ & $\begin{array}{c}\% \text { da } \\
\text { Produção }\end{array}$ & $\begin{array}{c}\text { Rácio } \\
\text { Exp/Imp }\end{array}$ & $\begin{array}{c}\% \text { da } \\
\text { Produção }\end{array}$ & $\begin{array}{c}\text { Rácio } \\
\text { Exp/Imp }\end{array}$ \\
\hline $1980-82$ & 46,6 & 41,9 & 14,9 & 11,7 & 27,1 & 7,3 & 11,4 & 3,7 \\
\hline $1983-85$ & 40,6 & 103,8 & 13,2 & 33,5 & 29,1 & 27,7 & 17,1 & 14,6 \\
\hline $1986-88$ & 37,5 & 1,0 & 13,8 & 5,2 & 25,6 & 6,1 & 23,1 & 4,9 \\
\hline $1989-91$ & 34,5 & 1,3 & 14,8 & 5,6 & 22,3 & 6,1 & 28,4 & 6,8 \\
\hline
\end{tabular}

fonte: INE, Estatísticas Industriais e do Comércio Externo

À primeira vista, estes elementos poderiam levar-nos a pressupor uma tendência para a crescente especialização em sub-sectores em que o custo do trabalho se assume como principal vantagem, em desfavor de outros, em que, por exemplo, a capacidade tecnológica é determinante. Não nos parece, contudo, que essa ideia seja generalizável. Desde logo, porque uma tal conclusão não leva em consideração outras determinantes da competitividade que não se expressam directamente nos custos de produção e que, neste ramo como em muitos outros, tendem a assumir papel de relevo (MATEUS, 1994). Esta e outras razões impõem, portanto, uma análise mais detalhada que permitirá aferir o valor daquela ideia geral.

\section{O PAPEL DAS DINÂMICAS EMPRESARIAIS E TERRITORIAIS NA RECONFIGU- RAÇÃO DO SECTOR CERÂMICO}

Como seria de esperar dado o lapso de tempo em análise, as linhas gerais da geografia e da estrutura empresarial deste ramo industrial não sofreram, ao longo dos últimos dez anos, uma alteração radical. De uma forma simplificada, eles caracterizam-se, por um lado, por uma distribuição regional dos estabelecimentos e do emprego quase exclusivamente limitada a uma faixa litoral a norte de Lisboa (figura 1), onde se individualizam algumas áreas de forte especialização, organizadas em torno de centros urbanos com uma larga tradição na cerâmica ${ }^{4}$. Por

\footnotetext{
${ }^{4}$ Numa obra do início do século, José Queiroz (Ceramica Portugueza, 1907) referia já a importância de Aveiro, Ílhavo, Coimbra, Caldas da Rainha ou Alcobaça como centros ceramistas de grande importância, que rivalizavam «em tradição e qualidade dos seus produtos», com Lisboa e Porto/V.N.Gaia.
} 
outro lado, pelo peso muito significativo das pequenas e médias empresas independentes, que detêm uma larga maioria dos estabelecimentos e são responsáveis por um volume considerável do emprego do ramo.

Mas, embora este quadro muito geral se tenha mantido, há traços de evolução que possibilitam uma melhor interpretação das dinâmicas em curso no sector e poderão dar indicações quanto ao seu comportamento futuro. Esses traços têm expressão tanto na distribuição regional como na estrutura empresarial.

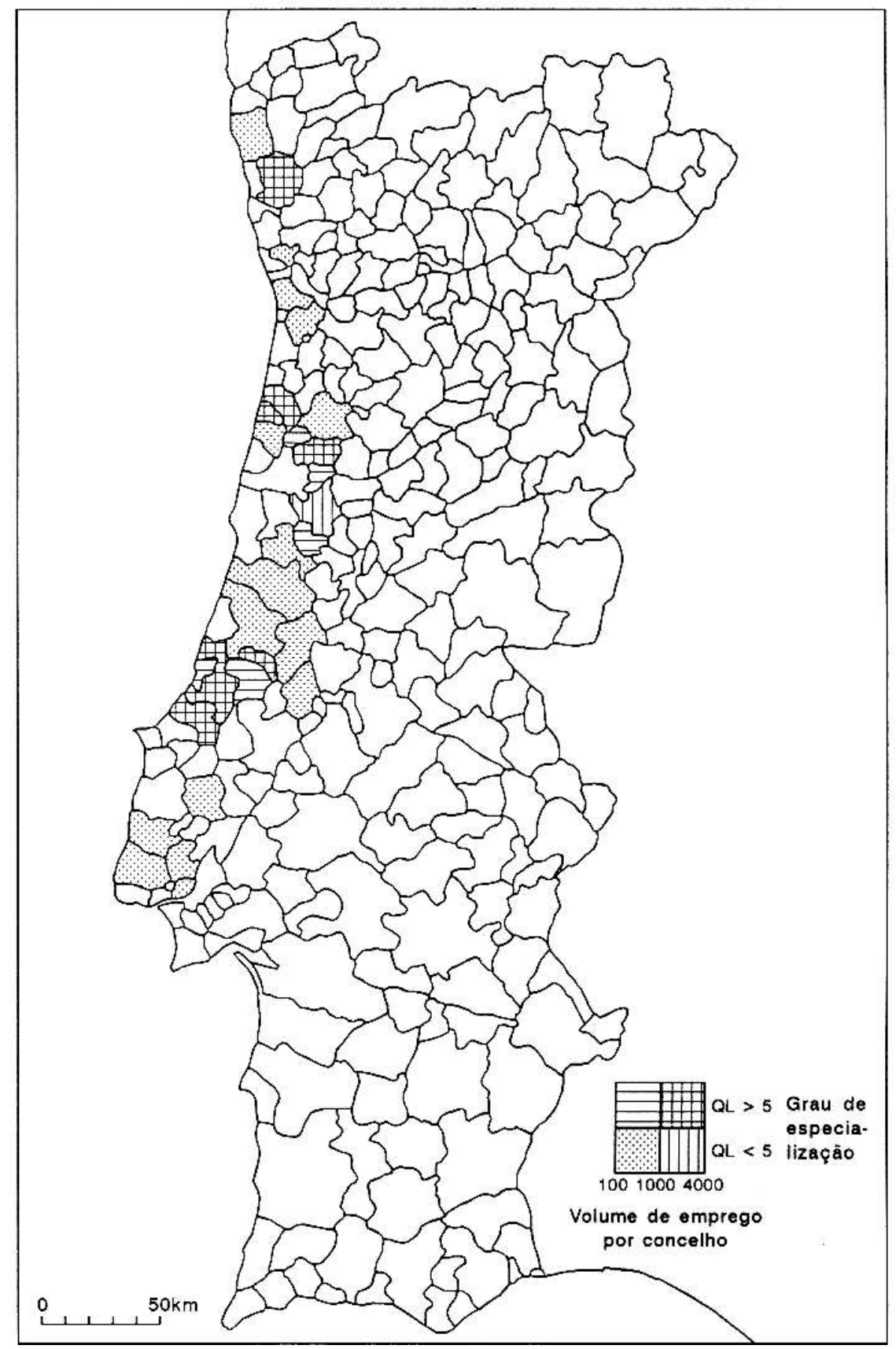



Figura 1 - Uma Geografia do sector da cerâmica fina.

Figure 1 - Une géographie des produits céramiques (porcelaine et faïence)

A evolução regional do emprego revela uma tendência bem vincada para a crescente concentração do sector nas duas áreas de maior especialização (quadro IV): a do Baixo Vouga, onde pontificam os concelhos de Aveiro e de Ílhavo, mas que progressivamente vai englobando os de Águeda, Oliveira do Bairro, Anadia e Vagos, e a do Oeste, que tem em Caldas da Rainha e Alcobaça os seus pólos mais importantes e se estende para norte, ao longo da Estrada Nacional $\mathrm{n}^{\circ} 1$, até à Batalha. Estas duas áreas eram responsáveis, em 1993, por mais de $60 \%$ do emprego nacional do ramo, registando ainda, em particular a segunda, o maior acréscimo do número de empresas. No entanto, outras áreas conseguem manter a sua importância relativa: a do concelho de Barcelos e, em menor grau, a retaguarda menos urbanizada da Área Metropolitana de Lisboa (cujo crescimento não é, no entanto, suficiente para compensar o decréscimo observado na cidade e na sua periferia imediata).

Quadro IV - Evolução da distribuição regional do emprego entre 1982 e 1993 (em \% do total) Tableau IV - Evolution de la distribution régionale de l'emploi, 1982 et 1993 (pourcentage du total)

\begin{tabular}{|l|l|l|l|l|}
\hline & & 1982 & 1993 & \\
\hline
\end{tabular}

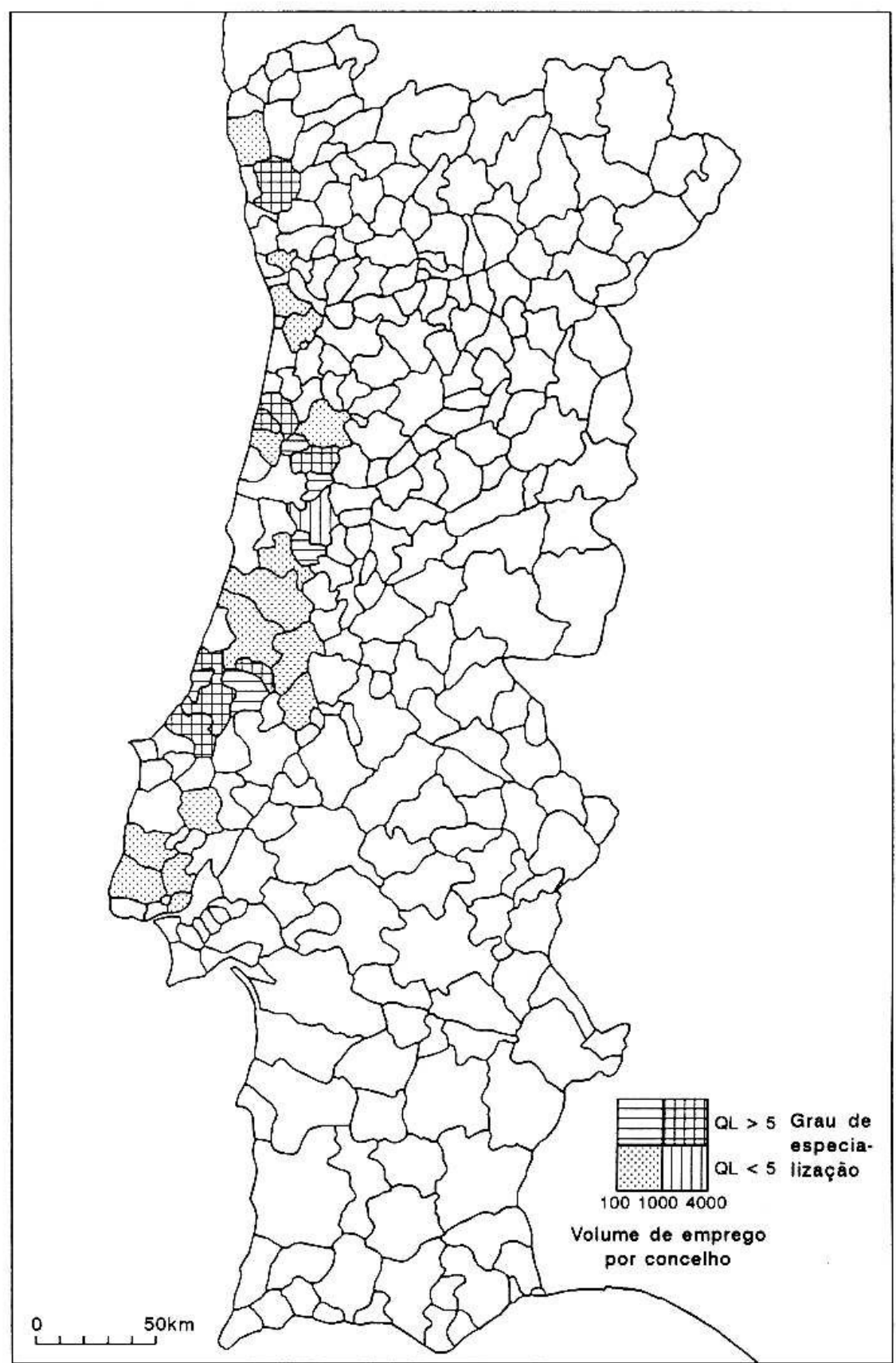




\begin{tabular}{|l|c|c|c|l|}
\hline & $\begin{array}{c}\text { Aveiro-Ílhavo e ou- } \\
\text { tros concelhos do } \\
\text { Baixo Vouga }\end{array}$ & 19.6 & 25.9 & \\
\hline $\begin{array}{c}\text { Caldas-Alcobaça- } \\
\text { Nazaré e eixo EN1 } \\
\text { até Batalha }\end{array}$ & 23.6 & 35.7 & \\
\hline $\begin{array}{c}\text { Coimbra e outros } \\
\text { concelhos do Baixo } \\
\text { Mondego }\end{array}$ & 16.0 & 11.3 & \\
\hline $\begin{array}{c}\text { Lisboa-Loures e } \\
\text { concelhos da } \\
\text { A.M.L. norte }\end{array}$ & 9.5 & 5.0 & \\
\hline $\begin{array}{c}\text { Barcelos e outros } \\
\text { concelhos do Minho }\end{array}$ & $\begin{array}{c}\text { V.N.Gaia e outros } \\
\text { concelhos da } \\
\text { A.M.Porto }\end{array}$ & 7.2 & 7.3 & \\
\hline
\end{tabular}

fonte: MESS

A evolução do emprego por dimensão dos estabelecimentos denota uma tendência igualmente bem marcada para a diminuição da dimensão média das unidades produtivas (quadro V). Este é o resultado de dois processos que ocorrem em simultâneo: um acréscimo muito grande do número de pequenas empresas que, como anteriormente se referiu, tem a sua máxima expressão no período de forte expansão do ramo, nomeadamente após a adesão à CEE, e de processos de downsizing nos maiores estabelecimentos, associados a estratégias de flexibilização na gestão do emprego.

Quadro V - O emprego por dimensão dos estabelecimentos, em 1982 e 1993 (em \% do total)

Tableau V - L'emploi selon la dimension des établissements, 1982 et 1993 (pourcentage du total)

\begin{tabular}{|c|c|c|c|c|}
\hline & $\begin{array}{c}\text { Estab. <50 } \\
\mathrm{emp}\end{array}$ & Estab. 50 a 199 & Estab. 200 a 399 & Estab. > 400 \\
\hline 1982 & 14.6 & 26.8 & 11.4 & 47.2 \\
\hline 1993 & 24.5 & 34.8 & 13.8 & 26.9 \\
\hline
\end{tabular}

Fonte: MESS

No entanto, estas evidências estatísticas apenas superficialmente traduzem as dinâmicas em curso no sector, pelo que o recurso a fontes de informação directas se reveste de uma importância decisiva. Uma análise das características essenciais dos tecidos produtivos mais significativos para este ramo e da sua evolução recente (para o que confluem factores tão diversos como as estratégias empresariais predominantes em cada uma destas áreas ou a acção dos poderes públicos) revela o desenvolvimento, neste período, de duas dinâmicas fundamentais e, em certa medida, antagónicas, mas que confluem no sentido de uma progressiva afirmação das áreas de maior especialização ${ }^{5}$.

A primeira dinâmica traduz-se no aprofundamento de uma lógica de exploração das vantagens comparativas que algumas destas áreas ainda detêm. Alguns aspectos associados à sua tradição no ramo permitem manter a sua capacidade de

\footnotetext{
${ }^{5}$ As ideias que, neste ponto, se expõem baseiam-se, em grande medida, nos resultados do estudo já citado (Feio, 1995) actualizados recentemente através de um inquérito postal.
} 
atrair investimentos, tanto locais como de grupos económicos nacionais ou estrangeiros. Entre eles destacam-se os relacionados com as características da mão-de-obra (abundância, cultura técnica e custo), mas incluem-se igualmente outros, associados às acessibilidades, às infraestruturas, à disponibilidade de outros factores de produção ou ao nível de oferta de serviços.

Grande parte das filiais de empresas estrangeiras recentemente instaladas segue um tipo de estratégia que se enquadra perfeitamente nesta dinâmica geral. A forma como essas empresas se integram nos tecidos regionais tem, por isso, efeitos relativamente ténues, nomeadamente no plano tecnológico.

Mas esta lógica é ainda comum a grande parte das empresas de base local. Entre elas prevalece o que se pode designar por uma estratégia globalmente defensiva. Neste caso, as empresas concorrem essencialmente com base no preço dos produtos, tirando partido de uma utilização flexível dos recursos locais (definida em função das flutuações da procura) e do desenvolvimento de estratégias de redução de custos, muitas vezes assentes nos baixos salários ou na precarização das relações contratuais. Para esse objectivo contribui, de forma sensível, a pequena dimensão dos seus estabelecimentos e a simplicidade da sua estrutura produtiva. Uma tal estratégia global está ainda geralmente associada a níveis tecnológico, de organização e de gestão relativamente baixos, bem como a uma posição subalterna no mercado que se traduz num fraco poder contratual. As situações muito comuns de empresas fornecedoras de agentes internacionais, em regime de subcontratação da fase de produção, sem qualquer intervenção nas etapas a montante ou a jusante desta, são exemplos explícitos dessa posição subalterna.

Esta lógica é particularmente evidente nas áreas onde a industrialização difusa se articula com as actividades rurais, nomeadamente nos concelhos do Oeste e do Minho.

A segunda dinâmica traduz-se na criação e reforço de novos factores de competitividade, assentes no desenvolvimento de estratégias empresariais ofensivas, estimuladas, em maior ou menor grau, pelas políticas públicas e pela evolução do contexto territorial em que se inscrevem.

Estas estratégias caracterizam-se, em geral, pela valorização de factores como a qualidade e a inovação dos produtos, que implicam um investimento significativo nas fases complementares da produção (projecto e design, controle de qualidade, estudos de mercado e marketing), e pelo aumento da produtividade baseada na inovação tecnológica e na capacidade de gestão. Estão ainda geralmente associadas à procura de um posicionamento forte face aos mercados, nacionais ou internacionais, em que o controle dos canais de distribuição, ou pelo menos a salvaguarda de algum poder negocial com as redes comerciais, assume particular importância.

Este tipo de estratégia está naturalmente associada às empresas mais apetrechadas do ponto de vista organizativo o que, na maioria dos casos, corresponde às de maior dimensão e inseridas em grupos económicos. A tendência observada para a concentração empresarial - expressa nas fusões e aquisições verificadas nos últimos anos e que envolveram alguns dos mais importantes grupos e empresas do ramo - não pode dissociar-se da tentativa de obtenção de um limiar mínimo de dimensão capaz de propiciar o melhor desenvolvimento de um tal tipo de estratégia.

Contudo, os exemplos de pequenas e médias empresas, nomeadamente na região Oeste, que individualmente ou associadas - tanto numa lógica de rede de cooperação como de grupos não formalizados - procuram desenvolver, ainda que 
parcialmente ou de forma embrionária, uma nova relação com os mercados, que passam nomeadamente por formas de internacionalização activa, traduzem uma postura estratégica similar. É sobretudo nestes casos que a envolvente territorial assume uma importância decisiva, permitindo que essas empresas encontrem no meio em que se inscrevem as condições que a sua dimensão ou estrutura interna não lhe permitiriam obter. Esta segunda dinâmica tem expressão, por isso, tanto nas áreas onde as estruturas empresariais são mais evoluídas (no conjunto da região de Aveiro ou na cidade de Caldas da Rainha) como naquelas onde o grau de coesão do tecido socio-produtivo é mais elevado.

Os indicadores por distrito referidos no quadro VI ilustram, em parte, o que se tem vindo a afirmar ${ }^{6}$. $O$ distrito de Aveiro reforça a sua posição na produção nacional do ramo fundamentalmente à base de um aumento da produtividade, a que não será estranha a conjugação de uma estrutura empresarial muito influenciada pelo peso das maiores empresas, de uma maior presença de sub-sectores mais intensivos em tecnologia e de condições locais favoráveis (nomeadamente no domínio das infraestruturas, do nível de oferta de serviços, das acessibilidades ou das características da mão-de-obra). No distrito de Leiria, pelo contrário, o menor custo do trabalho parece continuar a constituir a base da sua competitividade. Porém, como atrás se referiu, este facto não constitui uma tendência geral, dado que as duas dinâmicas referidas coexistem, em particular na área de maior especialização polarizada por Caldas da Rainha. Os indicadores relativos aos restantes distritos, que tendem a perder importância relativa na produção do ramo, sugerem trajectórias distintas, com destaque para o do Porto onde uma dinâmica de reforço da competitividade, assente em algumas unidades de maior dimensão, parece sobrepor-se a uma certa erosão das vantagens comparativas tradicionais que afecta sobretudo as pequenas empresas.

Quadro VI - Alguns indicadores económicos por distrito (1980-81 e 1988-89)

Tableau VI - Quelques indicateurs économiques par distrito (1980/81 et 1988/89)

\begin{tabular}{|c|c|c|c|c|c|c|}
\hline \multirow{2}{*}{ distrito } & \multicolumn{2}{|c|}{$\begin{array}{c}\text { VAB } \\
\text { (\% do país) }\end{array}$} & \multicolumn{2}{c|}{$\begin{array}{c}\text { produtividade aparente } \\
\text { (país=100) }\end{array}$} & \multicolumn{2}{c|}{$\begin{array}{c}\text { nível de remunerações } \\
\text { (país=100) }\end{array}$} \\
\hline & $80-81$ & $88-89$ & $80-81$ & $88-89$ & $80-81$ & $88-89$ \\
\hline Aveiro & 28.5 & 46.7 & 119 & 124 & 104 & 102 \\
\hline Braga & 0.6 & 0.4 & 76 & 85 & 31 & 55 \\
\hline Coimbra & 25.6 & 12.2 & 128 & 81 & 102 & 107 \\
\hline Leiria & 21.5 & 26.6 & 91 & 78 & 94 & 89 \\
\hline Lisboa & 9.9 & 3.9 & 76 & 85 & 103 & 107 \\
\hline Porto & 13.4 & 9.0 & 100 & 163 & 111 & 146 \\
\hline
\end{tabular}

\footnotetext{
${ }^{6}$ A inexistência de elementos estatísticos mais desagregados e actualizados obriga à utilização dos que se apresentam. Têm, por isso, um carácter meramente indicativo, dado que nem os dados por distrito têm correspondência exacta com os das áreas referidas no texto, nem o período de 1988-89 é o mais indicado para exemplificar a situação presente. Registe-se ainda que a amostra utilizada pelo INE não contempla as muito pequenas empresas, de que resulta uma subavaliação dos distritos onde elas são muito significativas, como é o caso de Braga.
} 


\section{UMA SÍNTESE E ALGUMAS CONCLUSÕES}

Os diferentes aspectos focados ao longo deste estudo permitem estabelecer, em termos de síntese final, algumas notas conclusivas.

Em primeiro lugar, parece incontestável que a integração europeia acelerou o processo de internacionalização do sector que temos vindo a analisar, o que é particularmente evidente na evolução do comércio externo (tanto no reforço da componente exportadora como no grande crescimento das importações), mas se expressa igualmente na evolução dos fluxos de investimento e das relações contratuais entre empresas nacionais e estrangeiras. Esse facto traduz uma alteração radical do quadro geral em que as empresas se inserem, dado que o alargamento dos seus horizontes de mercado é acompanhado por uma concorrência acrescida.

Em segundo lugar, são notórias grandes diferenças na capacidade de resposta a esta transformação irreversível. A análise dessas diferenças não é operativa, no entanto, no plano sectorial. Ainda que se notem modificações sensíveis no peso relativo dos diferentes sub-sectores da cerâmica fina, existem casos de sucesso e de insucesso em qualquer um deles. Pelo contrário, a análise das estratégias das empresas em estreita relação com a das dinâmicas territoriais revela-se bem mais frutuosa.

Podem destrinçar-se duas dinâmicas fundamentais cujos efeitos se reflectem, já hoje, nas performances e na distribuição regional do emprego do ramo: uma assente no prolongamento da lógica mais tradicional de exploração das vantagens comparativas de algumas áreas; outra baseada na criação de novos factores de competitividade, para o que determinadas condições territoriais não deixam, também, de ser importantes.

Nesse sentido, é possível concluir que a importância crescente da cerâmica decorativa na produção e nas exportações nacionais traduz, em grande medida, o predomínio da primeira dessas dinâmicas, especialmente acentuada nas áreas em que uma especialização tradicional se associa a menores custos de produção. De facto, é aqui que a lógica das vantagens comparativas ainda permite algum crescimento. Contudo, deve ter-se presente que a concorrência movida nomeadamente pelos produtores asiáticos (China e Vietname, por exemplo) tenderá num futuro mais ou menos próximo a criar dificuldades acrescidas às empresas que desenvolvem as suas estratégias nessa óptica.

A segunda dinâmica está associada a uma parte das maiores e melhores apetrechadas empresas do ramo. No entanto não é uma sua característica geral e exclusiva. A evolução para estratégias mais elaboradas, mas certamente mais promissoras no futuro, está igualmente ao alcance de pequenas e médias empresas, nomeadamente das que beneficiam de um contexto territorial favorável. Não é demais, portanto, insistir na importância das medidas visando a consolidação dessas condições territoriais, como eixo essencial da política industrial.

Estas duas dinâmicas têm uma expressão espacial que se traduz numa concentração crescente em áreas muito especializadas, entre as quais sobressaem as do Baixo Vouga e do Oeste. Cada uma dessas áreas têm as suas potencialidades que a própria evolução tem posto em evidência, mas têm também fragilidades por exemplo, nos domínios da qualificação do emprego ou da capacidade de gestão do empresariado, da oferta de serviços qualificados ou dos níveis de intensidade e inovação tecnológica - que as políticas públicas devem ajudar a debelar. Da correcta definição dessas políticas dependerá, em grande medida, o seu futuro. O 
reforço da componente não-assistencial e de intervenção sobre o meio, preconizado pelo PEDIP II, parece traduzir uma atenção particular aos aspectos atrás referidos. Não se pode, no entanto, deixar de ter presente que da formulação dos objectivos à concretização das medidas há uma distância considerável a percorrer, em particular em domínios que exigem um grande esforço de concertação entre agentes e que não se traduzem em resultados económicos imediatos.

\section{BIBLIOGRAFIA}

MATEUS, Augusto (1994) - Reflexões para uma estratégia de especialização da região de Lisboa e Vale do Tejo. $1^{o}$ Forum de Lisboa e Vale do Tejo, AERLIS, Lisboa.

MONITOR Company (1994) - Construir as vantagens competitivas de Portugal. Forum para a Competitividade, Lisboa.

FeIO, Paulo Areosa (1995) - Território e Competitividade. Uma perspectiva geográfica do processo de internacionalização no sector da cerâmica. Dissertação de mestrado em Geografia Humana e Planeamento Regional e Local (policopiado). 